Article

\title{
Integration of the Infrastructure of Systems Used in Smart Cities for the Planning of Transport and Communication Systems in Cities
}

\author{
Cezary Stępniak $^{1}$, Dorota Jelonek ${ }^{1, *(1)}$, Magdalena Wyrwicka ${ }^{2}\left(\mathbb{D}\right.$ and Iwona Chomiak-Orsa ${ }^{3}$ \\ 1 Faculty of Management, Czestochowa, University of Technology, 42-201 Czestochowa, Poland; \\ cezary.stepniak@pcz.pl \\ 2 Faculty of Engineering Management, Poznan University of Technology, 60-965 Poznan, Poland; \\ magdalena.wyrwicka@put.poznan.pl \\ 3 Faculty of Management, Wroclaw University of Economics and Business, 53-345 Wroclaw, Poland; \\ Iwona.Chomiak-Orsa@ue.wroc.pl \\ * Correspondence: dorota.jelonek@pcz.pl
}

Citation: Stẹpniak, C.; Jelonek, D.; Wyrwicka, M.; Chomiak-Orsa, I. Integration of the Infrastructure of Systems Used in Smart Cities for the Planning of Transport and Communication Systems in Cities. Energies 2021, 14, 3069. https:// doi.org/10.3390/en14113069

Academic Editor: Ricardo J. Bessa

Received: 5 May 2021

Accepted: 23 May 2021

Published: 25 May 2021

Publisher's Note: MDPI stays neutral with regard to jurisdictional claims in published maps and institutional affiliations.

Copyright: (c) 2021 by the authors. Licensee MDPI, Basel, Switzerland. This article is an open access article distributed under the terms and conditions of the Creative Commons Attribution (CC BY) license (https:// creativecommons.org/licenses/by/ $4.0 /)$.

\begin{abstract}
Modern mobility and adaptation of transport and communication systems to the requirements of the inhabitants are both inseparable elements of the developed concept of smart cities. One of the important stages in the implementation of this concept is the planning stage, taking into account the complexity and a large number of determinants that impact the effectiveness of decisions related to the planning of transport, communication and logistic systems. The purpose of the article is to lay out a model of a system based on the integration of selected Internet of Things tools used in smart cities to support urban development planning processes in the scope of the ongoing modification of transport, public communication and logistic systems. The model was developed on the basis of the cooperation between the authors and the boards of selected cities' observations made during the authors' travels and on the basis of identification and analysis of IT systems types and ICT (Information and Communication Technologies) tools in use within the smart city concept. The need to integrate IoT tools in support of the smart city concept resulted from the synthesis of previous research experience and the existing gap between the capabilities and the scope of applications of the tools in discussion. The results of the analysis allowed to develop a procedure that in an automated way allows to improve the communication, transport and logistics order in the area of interested cities.
\end{abstract}

Keywords: smart cities; planning of transport and communication systems; Internet of Things

\section{Introduction}

The constantly increasing population of the planet brings numerous consequences, including the continuous growth of cities, which transform into agglomerations surrounded by a network of smaller towns or districts. More than half of the World's population now lives in urban areas [1]. This causes the commuting needs of the inhabitants of the metropolises to constantly increase, and the distance that the inhabitants cover on average every day is getting longer. This phenomenon applies not only to the global metropolises such as Tokyo [2], London [3], New York City [4], Paris [2], Berlin [3], Seoul [2] and Singapore [2], but similar problems have to be solved by the authorities of smaller towns with a population below 100,000 inhabitants.

ICT infrastructure, in the form of a smart city, is increasingly used to manage cities. The term smart cities is broad and resists simple definition, but it mostly refers to the use of digital technologies to produce data to increase cities' efficiency, improve their liveability and promote their safety [5]. The concept of a smart city itself is still emerging, and the work of defining and conceptualizing it is in progress. Many definitions of smart 
cities exist [6-9]. Regarding the definitions, a group of literature research focuses on the following four perspectives: technical infrastructure [10], application domain [11], data processing [10,12] and system integration [12].

A range of conceptual variants is often obtained by replacing "smart" with alternative adjectives, for example, "intelligent" [13] or "digital" [14].

Harrison et al. [10] describes a smart city as an instrumented, interconnected and intelligent city. Instrumented refers to the capability of capturing and integrating live real-world data through the use of sensors, meters, appliances, personal devices and other similar sensors. Interconnected means the integration of these data into a computing platform that allows the communication of such information among the various city services. Intelligent refers to the inclusion of complex analytics, modeling, optimization and visualization services to make better operational decisions [10].

The development of smart cities is affected by many factors, e.g., internal factors: citizen participation, leadership and infrastructure, external factors: the fourth industrial revolution, political will, stakeholders [15] and the implementation of Regional Business Spatial Community (RBSC) [16] and development of Smart and Connected Communities (SCC) [17], but the use of ICT and modern technologies is the main driver to the smart city development.

ICT systems of public administration offices, different types of agencies, municipal enterprises, as well as entities providing services to cities collect multiple types of data which can be used for various purposes. Usually, the extent of the data collected and then processed depends on the entity managing the system. It is worth noting, however, that some of the recorded data is not entered as forms for describing primary events but can be recorded in the form of electronic tags through the Internet of Things (IoT) tools.

New technologies have enormous social impact, creating major changes in industrial sectors and in all areas of society. Many initiatives are being carried out and the application of the Internet of Things (IoT) and other innovative technologies to the public services is a growing trend all around the world [18]. This concept, IoT, has now been named more broadly as Internet of Everything (IoE), meaning the useful information available to people generates value rather than just communication between things [19]. The other important recent technologies that have a huge potential to enhance smart city services are: big data analytics [20-22], cloud computing [23] and Blockchain Technology [24].

Smart cities are an example of how the use of IoT will help make objects smart via a combination of devices, sensors, electronic tags and advanced communication networks. The new intelligence of cities, then, resides in the increasingly effective combination of digital telecommunication networks (the nerves), ubiquitously embedded intelligence (the brains), sensors and tags (the sensory organs) and software (the knowledge and cognitive competence) [8]. Digital devices connected through the Internet are producing big amounts of data that can be turned into knowledge using computational power, a concept known as Big Data [25].

These tools are being used more widely and the question arises as to whether city authorities are aware of the purposes for which they can use them. Modern IoT tools are usually used separately, as dedicated to specific applications. However, the integration of data from different solutions of this type can provide significant added value in city management.

Referring to the subject of the journal's issue on energy savings in cities, the abovementioned problems were referred to through the prism of communication and transport systems' improvement. This paper assumes that by shortening transport routes and communication lines, one can save fuel, and at the same time reduce exhaust and noise emissions. IoT tools in smart cities can be used to plan new communication, transport and logistic routes.

The purpose of the article is to lay out a model of a system based on the integration of selected Internet of Things tools used in smart cities to support urban development planning processes in the scope of the ongoing modification of public transport and 
communication and logistics routes in cities. Based on the analysis of available solutions used in the field of ICT and IoT tools, current applications and potentially available data, a model of integration of selected tools that can dynamically support the development of cities in terms of public transport infrastructure, communication and the logistic system was proposed. The model was developed on the basis of the cooperation between the authors and the boards of selected cities and on the basis of identification and analysis of system types in use within the smart city concept in various cities around the world.

The model can be applied in cities with an appropriate infrastructure of IoT tools and applying integrated IT systems and GIS technology. It involves the integration of these tools, thanks to which it is possible to dynamically collect data which can be used to plan new communication, transport and logistic solutions. When implementing the model, it is important to ensure that there is an appropriate organizational atmosphere among the stakeholders who are actually or potentially involved in the issues in the city.

\section{Materials and Methods}

Spatial planning plays an important part in tackling the issues of mobility and can reduce the growth in car traffic. The intention is also to reduce energy consumption [26]. Urban development planning $[27,28]$, similarly to urban spatial planning, is a multi-faceted issue. It does not only refer to the designation and location of appropriate urbanization zones or the transport, communication and logistic system, but numerous factors must also be taken into account, such as:

- Environmental factors, e.g., creating cities in such a way as to reduce air and noise pollution,

- Historical (preserving the historical value of a given city),

- Economic, e.g., reducing the costs of creating city infrastructure as far as possible,

- Safety, e.g., possibility of evacuating inhabitants in case of an emergency.

Appropriate city planning should promote shortening of transport connections and better commute for its inhabitants, guests and other stakeholders, and facilitate the accessibility of goods and services through continuous optimization of logistic networks. Discussions regarding various aspects of spatial planning, e.g., planning the structure of the transit network as a solution that will improve mobility in the city [29], the demand for public transport [30], the improvement of logistic systems and the principles of spatial planning [31], are found in the literature.

From the energy-related point of view, shortening transport routes is often associated with reconstruction of the utilities infrastructure (utilities infrastructure, e.g., water and sanitary, gas, electric or district heating systems, is very frequently built along with the construction of new transport routes in cities), which usually leads to a reduction in the distance travelled by inhabitants on their commute to work, school, shopping, etc. Reducing commute distances usually involves shortening the time needed to travel, which, for example, can result in more time for rest and leisure, but also usually involves a reduction in fuel consumption and reduced emissions, which can have positive environmental effects. It may also mean a reduction of losses associated with shortening the flow of resources in pipelines or transmission lines.

The development of appropriate solutions in this area is a complex undertaking and requires aligning three types of factors: technical/technological, informational and organizational [32]. In practice, aligning these factors usually takes time and investment processes are complicated procedures. It may even happen that before a given investment is completed, its importance will significantly decrease in favor of potential parallel investments. It is known that cities are living organisms and do not always develop according to the assumptions of their boards.

Therefore, the question arises of how to speed up investment processes and how to choose the investments most crucial in a given situation, as all planned investments must take into account financial conditions. 
This article discusses the use of ICT systems used by city boards, social networks and regional digital communities, as well as various types of Internet of Things tools used in different cities within the smart city concept to plan the development of the communication, transport and logistic infrastructure based on dynamically collected and processed data. If the city management boards agree to use appropriate tools, they can obtain data on the development of investment needs on an ongoing basis. These tools record a considerable amount of data that can be used for different purposes-obviously, preserving the ownership of the data and respecting the privacy of the persons and entities concerned.

The collected and processed data can be divided into two groups. The first is source data, which are recorded on the basis of primary events, e.g., complex forms or electronic tags, while the latter are processed data, largely non-addressable, i.e., they are composite indicators on the basis of which it is impossible to identify the entities to which the data relate. The processed data are used for analytical, control and decision-making purposes.

In these considerations, the issues of using the tools discussed are limited to designation and construction of new communication routes with the designation of closed zones, e.g., the German Umwelt zone and setting the directions of public transport and logistic networks' development.

The impulse to prepare this paper was an attempt to organize the knowledge on urban development planning by the authors. After the analysis of organizational issues related to the study of the possibility of creating regional communities (RBSC), which by using common GIS tools could support each other in defining urbanization zones and planning investments, it was time to study technical and technological issues. The concept of smart city assumes the use of many tools. They have specific functions and are utilized in different ways in cities. This article attempts to analyze whether the tools already in use can be integrated and what effects this can bring. As an additional requirement, the issue of the dynamics of data collection and processing is put forward, so that decision support can be based on constantly updated data.

For the purpose of this paper, a relatively narrow range of potential applications has been chosen, namely those related to supporting decision-making processes in the building of communication routes and public transport networks, bearing in mind that both issues may have an impact on energy consumption and savings, and also facilitate availability of goods and services. In addressing this topic, it was realized that different cities use different tools and that their functional scope and data collections may also differ. Despite these differences, it was assumed that these tools could be integrated, especially since most of them were ordered by the respective city or agglomeration authorities. However, the data collected by them can be visualized spatially using GIS technology. The use of this technology by city councils is becoming increasingly common.

The research for the purpose of this study followed two main directions. First of all, an attempt was made to recognize what type of ICT tools are used in the indicated area. Data has been collected on the basis of three main actions:

- Cooperation with local governments and the social activity of the authors.

- $\quad$ Experiences from visits to various cities around the world.

- Analysis of tourist and automotive portals describing the principles of road use and public transport in different countries.

The second direction is the analysis of data that can be collected by ICT tools used within smart city solutions. In this case, these are different tools ranging from nationwide information systems to selected technologies that can be used locally, but it is also possible to create a tool to manage these solutions remotely by collecting data online across the city or agglomeration. However, collecting data on the basis of electronic tags may constitute a violation of the law or at least of the privacy of its inhabitants (for example, the widespread use of registration plates recognition systems and recording of city monitoring data may mean that the relevant city unit can track inhabitants in cars and face recognition systems can track people using public transport). Therefore, at least part of the data can only be 
recorded by means of aggregation algorithms, where it will not be possible to obtain the source data.

Previous work on organizational issues related to the use of ICT tools by city boards has also been used in this reflection. Therefore, when developing the model, attention was paid to the factor of investment process organization as one of the conditions $[27,33]$.

The feasibility of a project based on the proposed model is determined by a technical and technological factor. In a city without a suitable smart city infrastructure, the use of the model will not be feasible.

On the other hand, decisions to establish new urbanization zones, road, logistic networks and infrastructure investments, including public transport, depend on organizational factors. Organizational factors are not always in line with the needs calculated on an online basis. What follows, the ranking of investment needs can change dynamically, while an investment process usually takes a few years from the start of work on the investment to commissioning.

The model proposed in this study is intended to indicate a dynamic ranking of the investments most needed at present. In a way, it suggests to city boards what investments should be made in the nearest future and how to carry out spatial management in the city by locating appropriate urbanization zones. Taking into account the fact that the data is collected and processed online, the presented ranking may change, e.g., as a result of new housing estates or shopping and service centers' construction. As mentioned above, the starting point is the smart city technical and technological infrastructure. This infrastructure should include the following:

- Civil registration systems

- Registration systems for businesses and other organizations

- Vehicle registration systems

- Road register

- Public transport management systems

- Supply and logistic networks in a city

- City geoportals

- Registration and planning systems for city investments (integrated with city geoportal)

- Tax calculation systems (in particular, ad valorem property taxes)

- Regional Business Spatial Community

- Traffic monitoring systems (including devices for recording traffic offences)

- Traffic counting systems

- Stationary exhaust gas analyzers

- Electronic tickets for public transport (city railway (German S-bahn), underground, trams, buses)

- City parking services

- Air monitoring systems

- Noise recording systems

The aforementioned ICT systems and tools may vary from city to city and their smart city infrastructure, and they can also depend on the country involved and regional culture. Furthermore, there is a great diversity in the world with regard to the systems of municipal authorities and their powers. Not all countries have the possibility of controlling the rules affecting the formation and development of cities.

However, assuming that a significant number of local governments have an impact on the development of a given city and implement further technologies related to the smart city concept, the list of ICT systems and tools presented above is an approximate set that can be used for the purpose of establishing new urbanization zones, the communication system and the logistic network of the city.

A list of presented tools is required to define the data to be recorded. The basic data to be collected should include:

- Population migrations (settlement locations, areas subject to depopulation). 
- Location of business entities, including large shopping centers and service zones as well as industrial areas (with potential negative impact on the environment).

- Values of plots of land in individual urbanization zones.

- Location of logistic warehouses and PUDO (Pick Up and Drop Off) points.

- Traffic routes (from starting point to destination).

- Map of traffic incidents (accidents and collisions).

- Routes of public transport passengers.

- City parking load.

- Data on air quality and noise intensity.

The data presented above may vary in nature and be managed by different departments of the city board. This means that in practice, it is not always possible to integrate them, as the different types of systems may not be connected to each other and data can be stored in different formats. The problem is that if the analyses are to be carried out online, communication between the data must also be ensured in this mode.

Another issue is that some of the data is of a source nature, but not all of them can be shared with others. Certainly, inhabitants of the cities would not want city boards to record their daily movements. In practice, there is no need for that. It is not important who travels along a given route, it is, however, important how many individuals travel along a similar route every day and whether these routes can be shortened.

There are two procedures to achieve this goal. There should be skillfully planned urbanization zones or new transport links built. These can be new arteries or new public transport infrastructure (city railway, underground, tram or even bus lines or aerial tramways).

The developed method is aimed at managing activities within a selected section of the city's functioning. It seems that the method can also be applied to other areas of community activity, such as healthcare, education or citizens' safety. The application of the method should follow the following seven steps:

1. Identification of organizational conditions,

2. Identification of applied IoT tools,

3. Identification of collected data resources,

4. Identification of problems in decision-making processes in management of selected areas,

5. Definition of integration platform for data processing,

6. Launching a procedure that supports functioning of a given area,

7. Control and dynamic modification of procedures.

In practice, the implementation of the proposed method depends on several important groups of factors, such as organizational, technological, informational or financial nature. The knowledge and willingness among the main decision makers in the city can also be an important factor.

\section{Results}

\subsection{Model of the System}

Two assumptions were made before the model was developed.

Assumption I: Different IoT tools are used in cities, and the model can only be used in cities that have the minimum infrastructure needed to collect relevant data and enable the integration of selected tools that will enable data processing in such a way that they can support decision-making processes. Cities in which a given condition is not met at the moment cannot apply the proposed model.

Assumption II: Municipalities are interested in dynamic planning of transport communication and logistic investments.

The model consists of two elements: the definition of movement, UI-determination of all routes within the transport system, and $\mathrm{UPT}$-routes of public transport described by means of Formulas (1) and (6) and the algorithm of applying the model to support decisionmaking processes in the field of new road, improvement of urban logistic networks and public transport investments. 
The formulas used in the model have been developed on the basis of the results of interviews (research interviews) with representatives of several cities' transport departments and observations of public transport and logistic systems in different cities and countries.

Some constants were adopted in the description of the model. However, their value may change depending on the city or country and the actual investment opportunities of a given board.

Communication links within cities and agglomerations are largely shaped by the layout of urbanization zones. Therefore, city boards may to some extent impact the development of cities through rational spatial management. In this respect, the establishment or reclassification of individual areas in cities is a key instrument. Of course, administrative decisions alone will not have an immediate effect, but they should be an incentive for inhabitants to settle or set-up businesses in a specific area. It is worth remembering that regardless of administrative decisions concerning the city's spatial management, the mobility of the population is influenced by other factors, such as the attractiveness of a given city or trends in population settlement. Furthermore, changes in residential settlement networks and business and administrative zones in cities lead to changes in urban logistic layout (especially last-mile systems).

When developing the model, the data issue cannot be omitted. Two types of data are needed to describe and apply the model. The first type concerns the variables defined in the model, while the second one consists in collecting data after practical launch of the system based on the presented model.

The first type of data should be defined by entities managing the planning and realization of communication, transport and logistic network investments. For each city, these will be different variables and will most often depend on investment opportunities of a given city or agglomeration.

The second type of data will be those collected by the system (ICT tools) developed on the basis of the model. The aforementioned system must integrate all necessary IoT tools used in a given city, which collect data within the framework of communication and transport. Technically, data recording can be carried out in three manners:

Firstly, it can be conducted through forms submitted by applicants. In this system, it becomes possible to determine the places of residence of the inhabitants and the populations of individual regions of the city, and it is possible to record the current layout of public transport and to describe its functioning, with the accuracy to individual transport lines. Data on logistic networks are collected by interested companies, mainly courier, express and parcel (CEP) operators. This type of data is usually recorded in the industry IT systems used in the management of a given city. Some of these systems are owned by the city, some are owned by the logistics operators, but some of them may be part of the state IT systems. Then, it is necessary to establish the rules of using the data recorded in the state systems.

Secondly, electronic tags that can be used by municipal Internet of Things tools, which include city surveillance systems integrated with vehicle registration plate recognition systems. For this purpose, an IT system is being created that allows for the collection of all the required data and at the same time converts addressable data into non-addressable data in order to not violate the right to privacy of residents. The above data may be complemented by those obtained from logistics companies on the transit or transport of goods (including the use of the capacity or volume of vehicles) and on delays resulting from the congestion of PUDO points. This allows for the construction of urban movement systems.

In order to start data collection, there is a need to have a tool model, which will define the purpose of its operation, the scope of collected data and procedures for its processing. In this paper, a model has been developed to define new routes and lines of public transport, and to improve last-mile logistics systems. Its aim is to shorten the routes, by constantly adjusting the last-mile network, which should allow for saving fuel and reducing harmful exhaust fumes and noise emissions.

The possibilities of shortening transport routes depend on the currently existing communication system or public transport. The model allows PUDO points to be continuously 
improved and logistical transports to be rationalized. Therefore, the starting point in the model was to build formulas describing car journeys, $\mathrm{U}_{\mathrm{I}}$ (Formula (1)), and public transport journeys, $\mathrm{U}_{\mathrm{PT}}$ (Formula (6)). Furthermore, in certain situations, the collected data can be verified based on the data from IT transport systems obtained from logistics companies operating in the city or agglomeration.

The formula of the movement system for cars is as follows (Formula (1)):

$$
\begin{aligned}
& \mathrm{U}_{\mathrm{I}}=\mathrm{S}(\mathrm{UZ} \text {, GPS coordinates }) \times \text { route }\left(\mathrm{N} \text { nodes, } \mathrm{GPS}_{1-\mathrm{n}} \text { coordinates }\right) \\
& \times \mathrm{F}(\mathrm{UZ}, \mathrm{GPS} \text { coordinates }) \times \mathrm{E}(\mathrm{A} \text { or } \mathrm{P} \text { or } \mathrm{G}) \times \mathrm{t}(\mathrm{min})
\end{aligned}
$$

where the components are:

- $\mathrm{U}_{\mathrm{I}}$-instance of movement-it is a set of all routes in the city/agglomeration picked up by the city monitoring system.

- $\quad$ S (UZ, GPS coordinates) - the starting point of the instance, the first monitoring station that captured a given vehicle, within UZ, will be the type and name of the given urbanization zone.

- $\quad$ Route (N nodes, GPS $_{1-\mathrm{n}}$ coordinates) - this is the route that is determined by a set of nodes (monitoring stations) that a given vehicle has passed through-instead of GPS $_{1-n}$ coordinates, which may be symbols of monitoring stations.

- $\quad \mathrm{F}$ (UZ, GPS coordinates) - the end point of the instance, the last monitoring station that captured the vehicle.

- $\quad$ E-type of vehicle (A-passenger cars, $\mathrm{P}$ - public transport, G-logistic services).

- $\quad t$ (min)-time counted in minutes (arithmetic mean for each instance) determines the length of the trip along a given route.

- $\quad \mathrm{x}$-Cartesian product.

Formula (1) describes the basic dataset that will be recorded for the ongoing monitoring of vehicle traffic in the city or agglomeration. However, after recording, the data will be sorted according to the adopted criteria.

The assumptions are that the data will be collected by the monitoring system in the city/agglomeration. At the monitored intersections, all vehicles are registered and saved as electronic tags. It should therefore be assumed that the number of journeys recorded by the monitoring system will be card $\left(\mathrm{U}_{\mathrm{I}}\right)$. After the end of the route, when the vehicle disappears from the monitoring system (it will not appear at any of the possible subsequent nodes), the data about each recorded journey will be processed and classified accordingly. Each recorded journey was marked with a symbol $\left(\mathrm{u}_{\mathrm{Ii}}\right)$. It should be assumed that the same vehicle may have multiple journeys.

Each journey will be analyzed against two criteria. The first will define the routes $R_{I}$. $R_{I}$ is the collection of all the distinguished routes used for the journeys. Each highlighted route marked $\mathrm{r}_{\mathrm{Ii}}$ will be described using the following elements (Formula (2)):

$$
\mathrm{r}_{\mathrm{Ii}}=\left\{\mathrm{S}_{\mathrm{i}}, \mathrm{N}_{\mathrm{i}}, \mathrm{F}_{\mathrm{i}}, \mathrm{d}_{\mathrm{i}}, \mathrm{L}_{\mathrm{i}}, \mathrm{K}_{\mathrm{i}}, \mathrm{C}_{\mathrm{i}}, \mathrm{T}\right\},
$$

- $\quad \mathrm{r}_{\mathrm{Ii}}$ - $\mathrm{i}$-th route, number of routes cannot be greater than card $\left(\mathrm{U}_{\mathrm{I}}\right)$, and in practice should be significantly smaller,

- $\mathrm{S}_{\mathrm{i}}$ - the starting point of the $\mathrm{i}$-th route,

- $\mathrm{N}_{\mathrm{i}}$-the arrangement of nodes on the $\mathrm{i}$-th route,

- $\mathrm{F}_{\mathrm{i}}$-the end point of the $\mathrm{i}$-th route,

- $\mathrm{d}_{\mathrm{i}}$-length of the $\mathrm{i}$-th route,

- $\mathrm{L}_{\mathrm{i}}$-distance between $\mathrm{S}$ and $\mathrm{F}$ in a straight line for the $\mathrm{i}$-th route,

- $\mathrm{K}_{\mathrm{i}}$-curvature of the route (see Formula (3)),

- $\quad \mathrm{C}$-number of journeys on a route calculated based on the respective $\mathrm{u}_{\mathrm{Ii}}$,

- $\mathrm{T}$-series containing the times of all journeys on a route.

The parameter $\mathrm{K}_{\mathrm{i}}$ is calculated for each route. In this way, all instances of movement $\left(\mathrm{U}_{\mathrm{I}}\right)$ will be defined with a description in the form of travel times and number of vehicles that have travelled the same route, and on the basis of GIS tools, the road $\mathrm{d}_{\mathrm{i}}$ in $\mathrm{km}$ and 
curvature of route $K_{i}$ will be calculated. The curvature of $K_{i}$ route will be calculated based on Formula (3):

$$
\mathrm{K}_{\mathrm{i}}=\mathrm{d}_{\mathrm{i}}(\mathrm{km}) / \mathrm{L}_{\mathrm{i}}(\mathrm{km}),
$$

where the components are:

- $\mathrm{K}$-curvature of the route,

- $\mathrm{d}_{\mathrm{i}}(\mathrm{km})$-route length for a given $\mathrm{r}_{\mathrm{Ii}}$,

- $\quad \mathrm{L}(\mathrm{km})$-distance between $\mathrm{S}$ and $\mathrm{F}$ in a straight line.

It should be assumed that unless the problem with specific terrain, e.g., mountainous terrain or terrain with special properties, or a city located around a lake, a bay, or a complicated water network occurs, the higher the value of the $K_{i}$ parameter, the greater the likelihood that the distance of a given route should be shortened.

The second important parameter is the number of journeys on the route. This is represented by the parameter C. However, it is important to note that a route may show segmental duplication of other routes. Therefore, the calculation of parameter $C$ should take into account all the routes compatible with the route analyzed. In such a case, the value of parameter $C$ will increase by the number of journeys on the routes containing the given route. In this paper, this increased parameter $C$ will be denoted $C_{+}$.

Furthermore, for each journey included in parameter $\mathrm{C}_{+}$, the journey time should be recorded. However, the vehicle registration numbers should not be recorded due to the protection of data of vehicles traveling through the city or agglomeration. In this case, the result of the data collection will be a time series containing as many elements as the value of parameter $\mathrm{C}_{+}$.

Furthermore, an important research issue is to determine the type of vehicles traveling through the city or agglomeration. From the point of view of the present article, individual journeys will be classified into one of the groups:

1. Passenger cars-(A),

2. Public transport vehicles (e.g., buses, trams, trolleybuses)-(P),

3. Delivery trucks (performing logistical tasks) - (G).

Consequently, the number of total journeys can be divided into journeys of individual types of vehicles. This is presented in Formula (4):

$$
\operatorname{card}\left(\mathrm{U}_{\mathrm{I}}\right)=\operatorname{card}\left(\mathrm{U}_{\mathrm{A}}\right)+\operatorname{card}\left(\mathrm{U}_{\mathrm{P}}\right)+\operatorname{card}\left(\mathrm{U}_{\mathrm{G}}\right),
$$

$\operatorname{card}\left(\mathrm{U}_{\mathrm{I}}\right)$ - the number of total journeys,

$\operatorname{card}\left(\mathrm{U}_{\mathrm{IA}}\right)$-number of passenger car journeys,

$\operatorname{card}\left(\mathrm{U}_{\mathrm{IP}}\right)$-number of journeys of public transport vehicles,

$\operatorname{card}\left(\mathrm{U}_{\mathrm{IG}}\right)$-number of journeys of commercial vehicles.

Following this reasoning, one can analogously identify the types of vehicles traveling along specific routes. This is described by Formula (5):

$$
\mathrm{C}_{+}\left(\mathrm{r}_{\mathrm{Ii}}\right)=\mathrm{C}_{+\mathrm{IA}}+\mathrm{C}_{+} \mathrm{IP}+\mathrm{C}_{+} \mathrm{IG}
$$

$\mathrm{C}_{+}\left(\mathrm{r}_{\mathrm{Ii}}\right)$-number of journeys on route $\mathrm{r}_{\mathrm{I}}$ and all routes covered by this route,

$\mathrm{C}_{+\mathrm{IA}}$-number of passenger car journeys,

$\mathrm{C}_{+\mathrm{IP}}$-number of journeys of public transport vehicles,

$\mathrm{C}_{+\mathrm{IG}}$-number of journeys of delivery trucks.

Data on $\mathrm{C}_{+\mathrm{IG}}$ can be partially or fully verified based on local regulations on rules for entry of specific types of vehicles into selected urban zones. It should also be added that the time series of journeys on a given route can also be divided into sub-series by vehicle type. However, the time of the trip $(\mathrm{t}(\mathrm{min}))$ will be recorded anonymously to the corresponding $\mathrm{U}_{\mathrm{I}}$. For analytical purposes, the routes with significant time differentiation will be particularly important. 
Based on the data collected above, it will be possible for each $\mathrm{r}_{\mathrm{Ii}}$ route to calculate the following parameters that are important for the functioning of the city or agglomeration:

- Estimated fuel consumption in urban traffic,

- Exhaust and noise emissions,

- Total journey time,

- $\quad$ Total mileage traveled to provide logistic services (including last mile).

From the point of view of the proposed model, the $C$ parameter for each $U_{I}$ is essential, but it cannot be calculated without recording the trips of all vehicles. Of course, its calculation can only be made on the basis of non-addressable data, in order to safeguard the right to privacy of drivers of vehicles passing through a given city. For this purpose, it is necessary to use appropriate algorithms that will record data on an incremental basis, and the data of each instance will be deleted when the instance is included in parameter $\mathrm{C}$ relevant $\mathrm{U}_{\mathrm{I}}$.

The second element of the urban transport system is public transport. Public transport, especially one that uses environmentally friendly means of transport, can reduce fuel consumption, emissions and noise. This effect can be achieved by building a public transport system that will encourage the shift from cars to public transport. This is especially possible if it is allowed to move relatively quickly and with a limited number of changes. In this case, data can be obtained from ticketing systems for public transport or passenger registration. In this case, it is important to collect data on the highest possible percentage of journeys for public transport vehicles, $\mathrm{U}_{\mathrm{PT}}$, and then to define all routes, $\mathrm{r}_{\mathrm{PTi}}$, and calculate the number of passengers $\mathrm{C}\left(\mathrm{r}_{\mathrm{PTi}}\right)$ for each of them. As with the analysis of vehicle journeys, all routes containing a given $\mathrm{C}_{+}\left(\mathrm{r}_{\mathrm{PTi}}\right)$ segment should also be considered. In the case of public transport, the formula of the transport system is as follows (Formula (6)):

$\mathrm{U}_{\mathrm{PT}}=\mathrm{S}(\mathrm{UZ}, \mathrm{GPS}$ coordinates $) \times$ route $(\mathrm{N}$ nodes $) \times \mathrm{F}(\mathrm{UZ}, \mathrm{GPS}$ coordinates $) \times \mathrm{t}(\mathrm{min})$

where the components are:

- $\quad \mathrm{U}_{\mathrm{PT}}$-instance of movement-is a set of all journeys of public transport.

- S (UZ, GPS coordinates) - the starting point of the instance, the first stop where the beginning of the trip has been registered, within UZ, will be the type and name of the given urbanization zone.

- $\quad$ Route (N nodes, $\mathrm{GPS}_{1-\mathrm{n}}$ coordinates) - a route that is marked by a set of interchange nodes, where the passenger has changed transport lines, instead of $\mathrm{GPS}_{1-\mathrm{n}}$ coordinates there can be symbols of stops or metro-stations.

- F (UZ, GPS coordinates) - the end point of the instance, the last stop where the passenger ends the trip.

- $\quad \mathrm{t}$ (min) - time counted in minutes (arithmetic mean for each instance) determines the length of the trip along a given route.

- $\quad \mathrm{x}$-Cartesian product.

On this basis, an analytical formula can be provided to order the data on public transport journeys, see Formula (7):

$$
\mathrm{r}_{\mathrm{PTi}}=\left\{\mathrm{S}_{\mathrm{i}}, \mathrm{N}_{\mathrm{i}}, \mathrm{F}_{\mathrm{i}}, \mathrm{d}_{\mathrm{i}}, \mathrm{L}_{\mathrm{i}}, \mathrm{K}_{\mathrm{i}}, \mathrm{C}_{\mathrm{i}}, \mathrm{T}\right\},
$$

- $\quad \mathrm{r}_{\mathrm{PTi}}$ - $\mathrm{i}$-th route of public transport journey; the number of routes cannot be greater than card $\left(\mathrm{U}_{\mathrm{PT}}\right)$, and, in practice, it should be significantly smaller,

- $\mathrm{S}_{\mathrm{i}}$ - the starting point of the $\mathrm{i}$-th route,

- $\mathrm{N}_{\mathrm{i}}$-the arrangement of nodes on the $\mathrm{i}$-th route,

- $\mathrm{F}_{\mathrm{i}}$ - the end point of the $\mathrm{i}$-th route,

- $\mathrm{d}_{\mathrm{i}}$-length of the $\mathrm{i}$-th route,

- $\mathrm{L}_{\mathrm{i}}$-distance between $\mathrm{S}$ and $\mathrm{F}$ in a straight line for the $\mathrm{i}$-th route,

- $\mathrm{K}_{\mathrm{i}}$-curvature of the route (see Formula (3)),

- $\mathrm{C}$-number of journeys on a route calculated based on the respective $\mathrm{u}_{\mathrm{PTi}}$,

- $\mathrm{T}$-series containing the times of all journeys on a route. 
Registration of passenger journeys may be more complicated, as it will force the creation of electronic tickets for public transport. The ticketing system for public transport in London may be used as a model. Another solution may be electronic tickets with chips based on technology used in the security gates in shops or shopping malls. The functionality of such tickets would be further enhanced by securing the entrance to public transport-possible only with a valid ticket. Of course, contact-free technology is assumed as standard.

Other types of electronic tags can also be used to address other issues. Data from such tags would be corrective in nature. These are mainly electronic tags that address environmental issues, e.g., measuring air pollution with particular emphasis on exhaust fumes or noise levels. In many cities, such systems operate on an ongoing basis to monitor the state of the environment. In this case, the development of those indicators at a specific level may also be a factor which will influence the investment plans of cities.

By using ticketing systems, it is possible to obtain a list of public transport routes $\left(\mathrm{R}_{\mathrm{PT}}\right)$, number of passengers on the same route $\left(\mathrm{C}_{\mathrm{rPTi}}\right)$ and travel time $\left(\mathrm{t}_{\mathrm{rPTi}}\right)$ in minutes-all journeys or daily statistical parameters (arithmetic mean, maximum and minimum travel time, standard deviation, quartiles, etc.). Using GIS technology, similarly as in case of car routes, it is possible to calculate curvature of route $\left(\mathrm{K}_{\mathrm{rIPT}}\right)$ according to Formula (3) calculated based on public transport routes.

Thirdly, there is the question of visualizing such a large amount of data. In this case, it may be helpful to use spatial technology based on GIS (Geographic Information System). The use of spatial technology can manifest itself in various ways. These may include city geoportals, Regional Business Spatial Community, GPS-based public transport control systems, city investment registration systems and other systems whose data can be visualized spatially (e.g., environmental data).

GIS technology is becoming increasingly more sophisticated and is now not only used to visualize maps, but also enables interactive object marking, linking to the descriptions of the objects included on maps, and enables various types of geographical and/or geometric analysis, enables collision analysis, cadastral systems (containing approximate valuations of plots) and can be used to build spatial decision models.

Taking into account the scope of the issue covered by the presented model, spatial technology is an important element for the visualization of descriptive data and constitutes a basic tool for modeling variants of new solutions. The prerequisite for this is that the GIS systems used must be integrated with selected thematic layers, i.e., systems responsible for collecting the required data. Integration may involve communicating GIS with individual IoT tools used in a given city or directly matching data streams to standards imposed by spatial technology.

The data available in GIS systems includes:

- Networks of movement systems (both vehicles and public transport),

- Data concerning investments in the city,

- Layout of urbanization zones,

- Environmental status of the city (current and selected periods),

- Traffic hazard maps,

- City logistics system.

In addition, data related to the following fields can be connected to GIS systems:

- Settlement layout of the city,

- Cadastral value of individual plots of land.

Taking into account the presented technology and the scope of collected data, it is possible to indicate the decision-making capabilities of the modeled system. Three parameters are the starting point for decision-making processes: $\mathrm{C}_{+}, \mathrm{K}$ and Dt-analyzed for each route, $\mathrm{r}$ (both for cars and public transport). An additional element should also be the use of individual $r_{I}$ routes in the urban logistic network system. This can be used for spatial visualization during the analysis of the routing of new transportation routes. In this 
case, this does not only concern the routes, but also the new locations of the nodes of the urban logistic network (warehouses, PUDO locations, etc.).

Parameter $C_{+}$is the number of all car or public transport journeys within each $\mathrm{R}$. It can be treated separately for each distinguished route or collectively for many different routes within a common section. Parameter $C_{+}$can be analyzed from different points of view:

- Current values-determining the volume of traffic on individual sections or the load on individual public transport lines.

- Historical variations, including sudden changes (usually resulting from the commissioning or closure or the renovation of other arteries/public transport lines).

- Analysis of changes in parameter $C$ in relation to changes taking place in the settlement layout of particular urbanization zones.

The parameter $\mathrm{K}$ indicates the differences between the actual route and the distance in a straight line between the start and end point ( $\mathrm{S}$ and F). It is also possible to perform an in-depth geometric analysis using nodal points, collision analysis or cadastral maps. These analyses should be performed for each $\mathrm{r}_{\mathrm{I}}$.

The third parameter will indicate the deviations during the travel along particular routes for both cars and public transport $R$. For each city, $\Delta t$ can be defined in different ways. It depends on the size of the city, the rules of planning its development or the available financial resources. The final method of calculation of the $\Delta t$ parameter will be undertaken by the city management boards or persons managing the city development planning/agglomeration departments.

$\Delta t$ may be a simple difference between the fastest and the slowest trip, but this type of data may be too simplistic, so selected statistics can be used to define a given parameter. Based on our own experience of cooperation with selected cities in Poland, the best suggested way to calculate $\Delta t$ would be to calculate the value of the difference between the 3rd quartile (Q3) and the 1st quartile (Q1) from all collected observations on each $r_{i}$. As a result, $\Delta t$ can be calculated according to Formula (8):

$$
\Delta \mathrm{t}=\mathrm{tQ} 3-\mathrm{tQ} 1
$$

where the components are:

- $\Delta \mathrm{t}$-difference in travel time,

- $\quad t Q 3$ - travel time equal to the 3rd quartile (Q3) counting from the fastest,

- $\quad$ QQ1-travel time equal to the 1st quartile value (Q1) counting from the fastest.

Then, the time differential (Dt) parameter is calculated for every $r_{i}$, see Formula (9):

$$
\mathrm{Dt}=\mathrm{tQ} 3 / \Delta \mathrm{t}
$$

The time differential $(\mathrm{Dt})$ parameter seems to take better account of the time difference (than $\Delta t$ ) because it can indicate whether there are large time differences in $R$ data drives after the most extreme drives have been rejected (too fast, probably traffic regulations were broken and too slow). The interpretation of Formula (9) is as follows: the lower the value of the Dt parameter, the more likely it is that there are large traffic problems. This is connected with excessive fuel consumption and increased emission of exhaust fumes and noise, and it is these paths that become candidates for analysis of whether an alternative public transport routes and lines, $\mathrm{R}_{\mathrm{ALT}}$, route should be built.

Other elements that should be taken into account include the problem of replacing car journeys with public transport journeys and the layout of urban logistic networks. The first issue is the use of urban IoT tools (urban interactive information screens in this case) to provide information about current traffic congestion and expected travel time by a car compared to travel by public transport.

Furthermore, logistics vehicle journey, $\mathrm{U}_{\mathrm{G}}$, will be included in the overall analysis of car journeys, but by changing the transport system, the new location of the logistic network 
nodes and the potential for using non-emission or low-emission modes of transport in the last-mile system can be analyzed.

Then, a threshold value should be determined, which may be different for each city. The analysis can be performed in two ways. The first is to rank all R's against Dt. Then, the analysis will start with the route with the lowest Dt value. Another option is to adopt a threshold value, the value of which will be determined by the relevant decision factors in the city/agglomeration. Urban GIS tools can visualize $r_{i}$ by the corresponding color intensity of the individual routes depending on the value of the parameter Dt. Furthermore, the thickness of the individual transport routes will indicate the number of journeys in the selected time unit $C_{+}$for each $r_{i}$.

As mentioned, the model can take corrective values. In this model, environmental parameters such as air pollution, in particular exhaust fumes, and noise levels are considered as such factors. The analysis should then focus on those sections that pass through areas with the worst parameters in terms of possibility to create alternative transport routes, or to lead low-carbon public transport (underground, tram or bus lines operated exclusively by electric vehicles, aerial tramways) to those areas.

The pre-investment analyses still need to take into account the trends. Please note that parameters $C$ for each $\mathrm{R}$ and $\mathrm{Dt}$ are counted online, so they will show variability over time. The functions of time trends in the variability of the indicated parameters should therefore be taken into account. The value of parameter $\mathrm{K}$ will change by leaps and should decrease for selected $r_{I}$ or $r_{P T}$ when a new artery or public transport line is put into use. However, it may also increase when, for example, some streets are closed due to renovation.

\subsection{Operating Principles of the Modeled System}

The operation of the modeled system should be analyzed in two aspects. On the one hand, the types of factors affecting the applicability of a given system must be taken into account. On the other hand, the planes of operation of the modeled system should be indicated.

As already mentioned, there are three types of factors that determine the commissioning of the modeled system:

- Technical and technological factors,

- Organizational factors,

- Informational factors.

The starting point are the technical/technological factors, in other words-the existence of an appropriate ICT infrastructure within the smart city framework in a given city. Without the appropriate ICT infrastructure, it is not possible to collect data, so it is also impossible to run the proposed system.

This infrastructure should present an appropriate density of coverage. If the infrastructure is full of blank spots, the cars or passengers will disappear too early in the system or the system will not correctly map their movement directions. The second technical and technological requirement is data compatibility within the system. Although different types of devices can be distinguished within the system, collecting different types of electronic tags, surveillance systems should reduce data to a form useful for the designed system and protect all rights of data owners and people whose behavior will be recorded.

The second type of factors relates to organizational issues. The research experience of the authors shows that this is a very significant problem. Many stakeholders may be involved in the organization of this project. Starting with city boards with many independent departments, various types of municipal agencies, independent service providers for city boards, media providers, IT companies, logistic companies and others.

In such a complex environment, where some actors are completely independent from city boards, it is difficult to reach a proper consensus. Not all actors will be interested in sharing data. One must also consider another important problem: as at least some of the entities operate independently of city boards, it may be difficult to take stock of the ICT systems and tools used within the smart city framework operating in individual cities. 
Therefore, in order for such solutions to be applied, it seems necessary to set-up appropriate research and development units with the goal of, on the one hand, collecting the reported needs or developing their own system models and, on the other hand, developing and implementing appropriate solutions. The operation of such units, depending on the countries and culture of a given country, may be based on a strong legal basis or authority developed through the implementation of subsequent projects, the usefulness of which will inspire respect among potential partners for cooperation.

The third type of factors relates to information issues. This issue is two-fold. The first level is the acquisition of source data, and the second is the construction of the decisionmaking models. While the issue of registration of source data has already been discussed before, the question of the operation of decision-making models arises. Actually, it is the ability to support decision-making processes that determines the value of the proposed tools. The operation of decision-making models can be presented using the following algorithm (Algorithm 1).

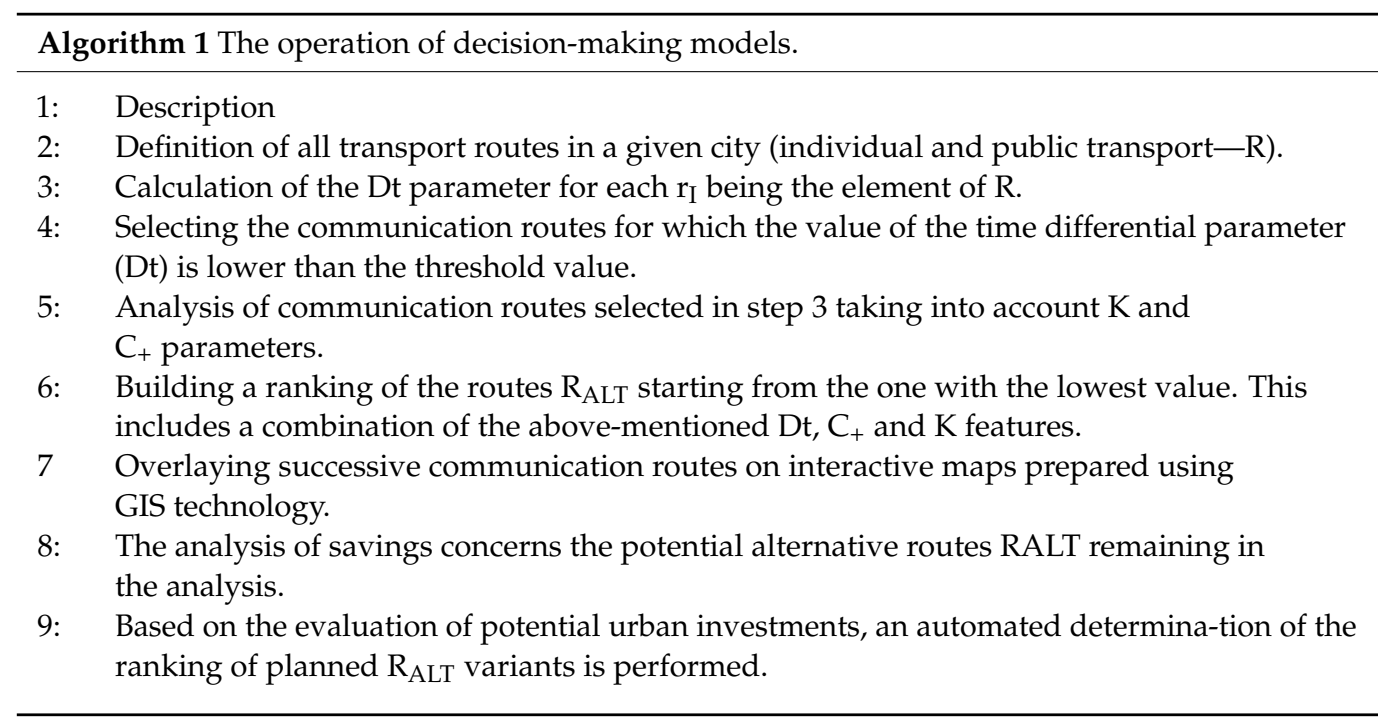

Step 1: Definition of all transport routes in a given city (individual and public transport (R)).

It will be performed on the basis of electronic tags from communication monitoring and public transport service systems. It is assumed that the source data should have a database describing the states from at least a one-year period, to take into account seasonal changes.

Step 2: Calculation of the Dt parameter for each $\mathrm{r}_{\mathrm{I}}$ being the element of $\mathrm{R}$. Dt will be calculated on the basis of unaddressed travel time data. Each time, the journey time is recorded, but it is not allowed to record who obtained the time. The travel times are then sorted from the shortest to the longest, so it is possible to calculate tQ1 and tQ3 for each $\mathrm{r}_{\mathrm{I}}$.

Step 3: Selecting the communication routes for which the value of the time differential parameter (Dt) is lower than the threshold value. The threshold value can be different for each city / agglomeration and depends on the decisions made by authorized entities.

Step 4: Analysis of communication routes selected in step 3 taking into account $\mathrm{K}$ and $\mathrm{C}_{+}$parameters. The starting point is geometric analysis of routes. It is based on the analysis of the curvature of a route (K parameter) with the question of whether it is possible to prepare a route layout shorter than the one used so far. As a result of this analysis, all those routes for which a shorter alternative cannot be built are rejected. For this purpose, geometrical analysis is used, supplemented by collision analysis. The collision analysis is based on the assumption that if the GIS system proposes a shorter route, it is necessary to check if there are any objects on the potential route that cannot be removed. Such a clause can be included in the ontological account, where the relation between types of 
object classes is defined. In this case, this involves objects that will have the value of a contradiction between them and the class of road objects or public transport systems. The city authorities may adopt threshold values for investments, which means that the possibilities of building alternative roads/transport lines appear if a certain number of users/passengers will be using the new route. Taking into account these two parameters, part of potential $R_{\text {ALT }}$ qualified for further planning works may be excluded. At this stage, it is also possible to estimate the amount of fuel consumption that can be saved. Calculations can result from determining the reduction in journey distance multiplied by the number of potential users, the anticipated reduction in journeys resulting from starting to use public transport and the reduction in the length of logistics vehicle journeys, $G$, as a result of a change in transport layout or the use of new green last-mile delivery types.

Step 5: Building a ranking of the routes $\mathrm{R}_{\mathrm{ALT}}$ starting from the one with the lowest value. This includes a combination of the above-mentioned $\mathrm{Dt}, \mathrm{C}_{+}$and $\mathrm{K}$ features.

Step 6: Overlaying successive communication routes on interactive maps prepared using GIS technology. Estimation of the approximate amount of costs that will have to be allocated for the implementation of the investment, performed with the help of the thematic layer-cadastre.

Step 7: The analysis of savings concerns the potential alternative routes, $R_{\mathrm{ALT}}$, remaining in the analysis. For each $R_{\mathrm{ALT}}$, the expected savings are calculated. The potential routes remaining for the analysis should be subjected to multi-criteria evaluation. The criteria for this evaluation and their weights should be defined by the representatives of the city authorities. For new transport routes, the potential basic parameters are:

- The highest values of the parameter K,

- The lowest values of the parameter Dt,

- Length of the planned section (the longer this distance, the more it should be taken into account as a future road investment),

- Number of $C_{+}$journeys: the more journeys, the more likely the investment,

- Converted index of logistics journey lengths: shortening of journey routes, taking into account the possibility of creating new logistic nodes,

- Calculation of the fuel efficiency index (by shortening the journey routes multiplied by the number of users and corrected by the travel time: reduction of fuel consumption by reducing the effect of traffic jams).

For public transport investments, the primary criteria for evaluating a potential investment are:

- The highest values of the parameter $\mathrm{K}$,

- The lowest values of the parameter Dt,

- Number of $C_{+}$journeys (passengers): the more journeys, the more likely the investment,

- Potential acquisition of a part of passengers previously traveling by car, which is analyzed in the case of new public transport lines located along the potential required transport routes (e.g., metro instead of the route),

- Exhaust and noise reduction indicators calculated based on the potential reduction in car traffic in the city.

Each city administration adopts its criteria for the evaluation of potential urban investments, guided, among other things, by the need to reduce exhaust and noise emissions, the introduction of restrictions on car traffic in the city center or even in the entire city, striving for the introduction of zero- or low-emission transport in the city, striving for withdrawal of large vehicle traffic (mainly $\mathrm{G}$ vehicles), etc. With low ecological awareness and culture and the actual communication needs, it is impossible to establish uniform criteria for all cities. Therefore, when planning investment processes, city authorities can define their own combinations of criteria and their weights.

In terms of ecological issues, the expected savings are calculated for each $\mathrm{R}_{\mathrm{ALT}}$ (alternative route). It may be counted over time, in assumed exhaust or noise emissions or in other units. Savings may be calculated in percentage or absolute terms. At this stage, it is 
also possible to determine the energy savings for each variant, assuming a shorter route, a faster journey with a time factor or moving from using one's own vehicle to the use of public transport.

Step 8: Based on the evaluation of potential urban investments, an automated determination of the ranking of planned $\mathrm{R}_{\mathrm{ALT}}$ variants is performed. The resulting list is a potential group of future urban investments.

An additional element is the logistic network nodes. They can be formed in two ways. With the city's transportation investments, the first is evaluation according to the algorithm presented above. The second way can take place with the development of urbanization zones. Without providing addressable data, demographic layers and layers referring to registered businesses and employment entities can be plotted on GIS maps. Consequently, the appropriate geometric functions of GIS tools can determine the next nodes of the logistic network. The precondition is access to the relevant registry systems according to legal regulations. This allows for the layouts of urban logistic networks, including last-mile layouts, to be improved on an ongoing basis.

The algorithm presented above can be supplemented with corrective values, for example, relating to environmental parameters or the issues of safety of traffic and public transport. These parameters can be used in both directions. On the one hand, highly polluted areas may be excluded from any traffic routes or only new roads. Collision analysis will be applied using GIS technologies.

Another solution may be that where there is a high level of environmental pollution, routes will be identified as sources of excessive emissions that need to be reduced. Then, a geometrical route is determined which bypasses the most threatened areas, or low-emission means of public transport can be introduced instead of roads in the identified area.

It should be added that the value of $\operatorname{card}(\mathrm{U})$ is subject to dynamic changes. This depends on the reference period and the data-recording principles. The reference period should last at least one year to take into account the effect of the seasons on changes in the trip parameters. Data collection, on the other hand, can be done with FIFO replacement. At the end of the day, the data for each $U$ shall be added, while, at the same time, deleting the data for the first day of the reference period. In more specialized tools, in addition to calculating the $\mathrm{Dt}, \mathrm{C}_{+}$and $\mathrm{K}$ parameters for each $\mathrm{R}$, it is also possible to use trend analysis of changes on individual routes $\left(\mathrm{r}_{\mathrm{I}}\right.$ or $\left.\mathrm{r}_{\mathrm{PT}}\right)$ and visualize this in real-time using GIS technology.

The algorithm presented above should be adjusted to the specificity of a given city. The study refers to tools used in selected European and Asian countries.

\section{Discussion}

The research experience of the authors shows that the mechanism that drives the application of smart city tools is technology development. It enables the implementation of various systems supporting urban management. Emerging new technologies or tools are in themselves a blank sheet. It is only their specific applications that allow their multi-faceted use. The key point is that many manufacturers of these technologies or tools operate on the market and they do not always know each other or want to cooperate with each other.

In addition, organizational and financial factors are frequently significant. The financial factor, in particular, may lead to abandoning the application of the proposed solutions.

Knowledge of the available tools and technologies and imagination of how to apply the solutions is another important factor. Without appropriate training and promotional activities, it is difficult to convince the selected entities to apply the modeled system.

Yet another issue is the culture of cooperation in the environment of stakeholders operating in individual cities. It is worth remembering that urban investment issues in the field of communication, public transport and logistics are a complex system of relationships between city authorities, municipal enterprises (e.g., city transport companies) and independent entities such as logistics and construction companies. It seems that this factor may be crucial for potential investments in the presented system model. 
This article was written from the perspective of city management. A very small section was selected for the application. Namely, the selection and integration of IoT tools within smart cities to support decision-making processes in the area of determining investment needs in the construction of new communication routes, public transport lines and improvement of urban logistic networks. The point is that very often, IoT tools have very narrow applications. Therefore, to solve specific urban issues, it is necessary to analyze the IoT tools used in a given city. Even seemingly similar issues such as routing in urban last-mile delivery cannot always be solved with the same model. However, in this case, it is important to analyze which IoT tools are available in the city.

Therefore, the main focus has been placed upon identifying the types of tools that can be integrated in order to achieve the desired objective. There are no specific technological solutions presented since the authors have noticed in their own research that different cities use different tools for the same purposes. Such diversity can occur in cities in the same region of a country, and it would therefore be difficult to identify universal tools on a global scale. This situation is due to the fact that city councils usually constitute an independent and self-funding public authority. This means that in different cities, the authorities may have different preferences regarding the implementation of further Internet of Things tools and information systems within the smart city framework.

Despite the indicated differences between different cities, it should be stated that the model itself is applicable. It can also be applied to other areas of smart city management. Of course, then it will be necessary to identify other IoT tools specific for this area and to develop other verification criteria. However, it is possible to apply it from a technical point of view. This is supported by the fact that more and more IoT tools will be used, and they will be able to generate more and more new types of data. GIS technology is also subject to continuous improvement, including becoming open to new types of data that can be presented in a spatial version. This makes it a tool for data integration. Moreover, it allows for joint visualization of collected data, which facilitates multi-criteria perception of smart city management.

\section{Conclusions}

The purpose of this article was to present a model of a system based on Internet of Things technologies used within the smart city framework. The model focuses on the identification of IoT tools and various types of ICT tools (with an important consideration for GIS technology), which can be used in the construction of the modeled system as well as a simplified algorithm of its operation. Thus, fulfilling the first criterion, feasibility.

Unfortunately, simply stating that such a tool is feasible is not a sufficient condition to start using similar tools. In this case, it was established that in order to implement a similar system, it is necessary to convince potential users of the system and to identify the investor and the entity that will manage the system itself. It will also be necessary to convince other stakeholders who will be able to benefit directly or indirectly from this implementation.

At present, the authors carry out observations aimed at analyzing the available tools operating within the Internet of Things technology, which have been presented in the literature recognizing the discussed issue. Their goal is to look for new possibilities of their application or a wider use of the data that these systems record. The tools and the data they collect have been selected solely for the purpose of the application, i.e., to dynamically support the modernization of transport and logistic networks and public transport. In the background of the analyzed applications, the problem of energy savings appears. Within the adopted scope, energy savings may result from two issues. The first is to shorten and improve the travel routes through the city. It can be assumed that especially in agglomerations, new routes are built in fast road standards, thanks to which the passage will not only be faster but also more efficient, e.g., thanks to collision-free intersections. However, the second issue seems to be more important. The development of public transport lines should encourage drivers to start using it. The change of behavior of inhabitants in this area should result in even greater savings in fuel consumption and 
support environmental protection. The scale of savings can be calculated by measuring the reduction of route length and the reduction of fuel consumption by decreasing the number of vehicles on the roads. The authors realize that an organizational and educational effort must be made to identify new opportunities arising with technological development. Furthermore, the effort to integrate stakeholders who will be able to use the modeled tools and technologies in the future is also important.

The integrating role of GIS technology should also be noted. Thanks to its visualization procedures and data processing capabilities (hyperlinks, interactive maps, geometric transformations, ontological analyses enabling collision analyses), it is possible to visualize a large amount of data at once, where the relationships between the phenomena of interest to the users can be visualized, etc.

To conclude, the proposed model of the system aims to promote the development of the transport, logistic and communication system of the city/agglomeration. It allows for dynamic identification of the most important current needs in the field of investment in line with smart cities.

As for the future of the model, as stated, the model is applicable. The thing is that its implementation in specific cities may be hindered by various barriers, e.g., organizational, financial, or even by a lack of knowledge about the information needs and opportunities brought by the use of specific IoT tools. The experience so far indicates that an important driver for the application of the model is the possibility of using more and more new IoT devices that can expand the scope of collected and processed information resources. On the one hand, it is important to coordinate the collateral investment in IoT tools, but on the other hand, the bottom-up initiative of individual stakeholders should not be drowned out. Therefore, the consilience factor should be considered as an important factor for developing the application of the proposed model. Research on this issue will not only help to detail the solutions in the proposed model, but will also be a factor in expanding the knowledge of the issues discussed above among potential stakeholders.

Author Contributions: Conceptualization, C.S., D.J., M.W. and I.C.-O.; methodology, C.S., D.J. and M.W.; writing-original draft preparation, C.S., D.J., M.W. and I.C.-O. (Introduction-D.J. and M.W., Materials and Methods and Results-C.S., D.J., M.W. and I.C.-O., Discussion and Conclusions-C.S. and I.C.-O.). All authors have read and agreed to the published version of the manuscript.

Funding: This research received no external funding.

Institutional Review Board Statement: Not applicable.

Informed Consent Statement: Not applicable.

Data Availability Statement: Not applicable.

Conflicts of Interest: The authors declare no conflict of interest.

\section{References}

1. Dirks, S.; Gurdgiev, C.; Keeling, M. Smarter Cities for Smarter Growth: How Cities Can Optimize Their Systems for the Talent-Based Economy; IBM Institute for Business Value: Somers, NY, USA, 2010.

2. Sorin-George, T.; Andreea, S. The world's smartest cities in the metropolitan century. Ovidius Univ Ann Econ Sci Ser. 2018, 18, 111-116.

3. Zvolska, L.; Lehner, M.; Voytenko Palgan, Y.; Mont, O.; Plepys, A. Urban sharing in smart cities: The cases of Berlin and London. Local Environ. 2019, 24, 628-645. [CrossRef]

4. Hall, R.E.; Bowerman, B.; Braverman, J.; Taylor, J.; Todosow, H.; Von Wimmersperg, U. The Vision of a Smart City; Brookhaven National Lab.: Upton, NY, USA, 2000.

5. Frith, J. Big data, technical communication, and the smart city. J. Bus. Tech. Commun. 2017, 31, 168-187. [CrossRef]

6. Albino, V.; Berardi, U.; Dangelico, R.M. Smart cities: Definitions, dimensions, performance, and initiatives. J. Urban. Technol. 2015, 22, 3-21. [CrossRef]

7. Boulton, A.; Brunn, S.D.; Devriendt, L. Cyberinfrastructures and "smart" world cities: Physical, human, and soft infrastructures. In International Handbook of Globalization and World Cities; Taylor, P., Derudder, B., Hoyler, M., Witlox, F., Eds.; Edward Elgar Publishing: Cheltenham, UK, 2011. 
8. Chourabi, H.; Nam, T.; Walker, S.; Gil-Garcia, J.R.; Mellouli, S.; Nahon, K.; Scholl, H.J. Understanding smart cities: An integrative framework. In Proceedings of the 45th Hawaii International Conference on System Sciences, Maui, HI, USA, 4-7 January 2012; IEEE: Piscataway, NJ, USA, 2012; pp. 2289-2297.

9. Yin, C.; Xiong, Z.; Chen, H.; Wang, J.; Cooper, D.; David, B. A literature survey on smart cities. Sci. China Inf. Sci. 2015, 58, 1-18. [CrossRef]

10. Harrison, C.; Eckman, B.; Hamilton, R.; Hartswick, P.; Kalagnanam, J.; Paraszczak, J.; Williams, P. Foundations for Smarter Cities. IBM J. Res. Dev. 2010, 54, 1-16. [CrossRef]

11. Giffinger, R.; Gudrun, H. Smart cities ranking: An effective instrument for the positioning of the cities? ACE Archit. City Environ. 2010, 4, 7-26.

12. Javidroozi, V.; Shah, H.; Amini, A.; Cole, A. Smart city as an integrated enterprise: A business process centric framework addressing challenges in systems integration. In Proceedings of the 3rd International Conference on Smart Systems, Devices and Technologies, Valencia, Spain, 20-24 July 2014; IARIA: Paris, France, 2014; pp. 55-59.

13. Komninos, N. The Age of Intelligent Cities: Smart Environments and Innovation-for-All Strategies; Routledge: London, UK, 2014.

14. Ishida, T.; Isbister, K. (Eds.) Digital Cities: Technologies, Experiences, and Future Perspectives; Springer Science \& Business Media: Berlin/Heidelberg, Germany, 2000.

15. Myeong, S.; Jung, Y.; Lee, E. A study on determinant factors in smart city development: An analytic hierarchy process analysis. Sustainability 2018, 10, 2606. [CrossRef]

16. Jelonek, D.; Stepniak, C.; Turek, T. The concept of building regional business spatial community. In Proceedings of the 2013 International Conference on e-Business (ICE-B), Reykjavik, Iceland, 29-31 July 2013; IEEE: Piscataway, NJ, USA, 2013 ; pp. 1-8.

17. Sun, Y.; Song, H.; Jara, A.J.; Bie, R. Internet of things and big data analytics for smart and connected communities. IEEE Access 2016, 4, 766-773. [CrossRef]

18. Díaz-Díaz, R.; Muñoz, L.; Pérez-González, D. The business model evaluation tool for smart cities: Application to SmartSantander use cases. Energies 2017, 10, 262. [CrossRef]

19. Cerruela García, G.; Luque Ruiz, I.; Gómez-Nieto, M.Á. State of the art, trends and future of bluetooth low energy, near field communication and visible light communication in the development of smart cities. Sensors 2016, 16, 1968. [CrossRef]

20. Al Nuaimi, E.; Al Neyadi, H.; Mohamed, N.; Al-Jaroodi, J. Applications of big data to smart cities. J. Internet Serv. Appl. 2015, 6, 25. [CrossRef]

21. Jelonek, D.; Stepniak, C.; Ziora, L. The meaning of big data in the support of managerial decisions in contemporary organizations: Review of selected research. In Advances in Intelligent Systems and Computing; Arai, K., Kapoor, S., Bhatia, R., Eds.; Springer: Cham, Switzerland, 2018.

22. Pérez-Chacón, R.; Luna-Romera, J.M.; Troncoso, A.; Martínez-Álvarez, F.; Riquelme, J.C. Big data analytics for discovering electricity consumption patterns in smart cities. Energies 2018, 11, 683. [CrossRef]

23. Khan, Z.; Anjum, A.; Kiani, S.L. Cloud based big data analytics for smart future cities. In Proceedings of the 2013 IEEE/ACM 6th International Conference on Utility and Cloud Computing, Dresden, Germany, 9-12 December 2013; IEEE: Piscataway, NJ, USA, 2013; pp. 381-386.

24. Biswas, K.; Muthukkumarasamy, V. Securing smart cities using blockchain technology. In Proceedings of the 2016 IEEE 18 th International Conference on High Performance Computing and Communications; IEEE 14th International Conference on Smart City; IEEE 2nd International Conference on Data Science and Systems (HPCC/SmartCity/DSS), Sydney, NSW, Australia, 12-14 December 2016; IEEE: Piscataway, NJ, USA, 2016; pp. 1392-1393.

25. Pérez González, D.; Díaz Díaz, R. Public services provided with ICT in the smart city environment: The case of spanish cities. J. Univers. Comput. Sci. 2015, 21, 248-267.

26. Meurs, H.; Haaijer, R. Spatial structure and mobility. Transp. Res. Part. D Transp. Environ. 2001, 6, 429-446. [CrossRef]

27. Jelonek, D.; Stepniak, C.; Turek, T.; Ziora, L. Planning City Development Directions with the Application of Sentiment Analysis. Prague Econ. Pap. 2020, 2020, 274-290. [CrossRef]

28. Mierzejewska, L.; Parysek, J.J. Integrated planning of the development of a city in terms of the diurnal activity of its residents. Bull. Geogr. Socio-Econ. Ser. 2014, 25, 143-153. [CrossRef]

29. Badia, H.; Estrada, M.; Robusté, F. Bus network structure and mobility pattern: A monocentric analytical approach on a grid street layout. Transp. Res. Part B Methodol. 2016, 93, 37-56. [CrossRef]

30. Paulley, N.; Balcombe, R.; Mackett, R.; Titheridge, H.; Preston, J.; Wardman, M.; White, P. The demand for public transport: The effects of fares, quality of service, income and car ownership. Transp. Policy 2006, 13, 295-306. [CrossRef]

31. McLeod, S.; Scheurer, J.; Curtis, C. Urban public transport: Planning principles and emerging practice. J. Plan. Lit. 2017, 32, 223-239. [CrossRef]

32. Stepniak, C.; Turek, T. Levels of the Use of Electronic Communities in the Management of Regions. In Proceedings of the 2015 Federated Conference on Computer Science and Information Systems (FedCSIS), Lodz, Poland, 13-16 September 2015; IEEE: Piscataway, NJ, USA, 2015; pp. 1551-1556.

33. Stepniak, C.; Turek, T. Possibilities of using GIS technology for dynamic planning of investment processes in cities. Procedia Comput. Sci. 2020, 176, 3225-3234. [CrossRef] 